Neurosurg Focus 20 (1):E8, 2006

\title{
Familial intracranial ependymomas
}

\author{
Report of three cases in a family and review of the literature
}

\author{
Vassilios G. Dimopoulos, M.D., Kostas N. Fountas, M.D., Ph.D., \\ AND Joe Sam Robinson, M.D. \\ Department of Neurosurgery, Medical Center of Central Georgia, Mercer University, School of \\ Medicine, Macon, Georgia
}

\begin{abstract}
Familial cases of intracranial ependymomas have been well documented in the literature. The authors present two cases from a family in which three members harbored intracranial ependymomas. A 54-year-old man with fourth ventricular ependymoma underwent resection of the tumor followed by radiation therapy. His son presented at age 36 years with a fourth ventricular tanycytic ependymoma and underwent total resection of the ependymoma with postoperative radiation therapy. The father's sister had been treated at another institution for a posterior fossa ependymoma. The association of ependymomas with molecular genetic alterations in chromosome 22 has been previously described. Further investigation of the genetic influences may lead to better therapeutic approaches for this relatively rare clinicopathological entity.
\end{abstract}

KEY WORDS • ependymoma • intracranial ependymoma • cytogenetics

Ependymomas are relatively rare CNS tumors derived from ependymal cells, which line the cerebral ventricles and central canal of the spinal cord, ${ }^{9,22}$ or from subependymal glial cells. ${ }^{6,22}$ They account for 1.9 to $7.8 \%$ of all neoplasms of the CNS. ${ }^{28}$ Several molecular genetic alterations have been reported to be involved in the pathogenesis of ependymomas, including abnormalities of chromosome arms $17 \mathrm{p}$ and $6 \mathrm{q}$ and chromosome 1 in pediatric populations $\mathrm{s}^{4,15,19,26}$ and a loss of chromosome arm 22q in 50-60\% of adult patients. $4,15,26,31,32$ Furthermore, the familial occurrence of ependymomas has been described in the literature. $5,12,20,25,27,33$

We report the cases of two members of a family in which three family members had ependymomas. The father and his son were treated for fourth ventricular ependymomas at our institution, and the father's sister was treated at another institution for an ependymoma of the posterior fossa.

\section{CASE REPORTS}

A 54-year-old man presented to our outpatient clinic with a long history of progressively worsening headaches. He denied any vertigo, gait disturbance, weakness, or sensory changes. His past medical history was positive for sleep apnea and severe hypertension. His family history revealed that one of his sisters had undergone resection of a posterior fossa ependymoma several years previously.

Neurologically, the patient was awake, alert, and oriented. His pupils were equal and reactive. His cranial nerves

Abbreviations used in this paper: $\mathrm{CNS}=$ central nervous system; $\mathrm{CT}=$ computerized tomography; $\mathrm{MR}=$ magnetic resonance. were grossly intact. He was ambulatory and had no motor or sensory deficits. His deep tendon reflexes were rated $2+$ bilaterally. The findings from the rest of his physical examination were unremarkable, and there was no clinical evidence of neurofibromatosis. Fundoscopic examination revealed obliteration of the optic disc margins bilaterally, with no hemorrhages or exudates.

A brain MR imaging study with contrast revealed the presence of an enhancing tumor arising from the floor of the fourth ventricle and extending through the foramina of Magendie and Luschka bilaterally. Mild ventricular dilation was also noted. Whole spinal axis MR imaging obtained for ruling out any drop metastases revealed caudal displacement of the cerebellar tonsils through the foramen magnum to the level of $\mathrm{C}-1$.

The patient underwent a midline suboccipital craniectomy with resection of the posterior arch of $\mathrm{C}-1$ with cranial nerve electrophysiological monitoring. The frozen section diagnosis favored ependymoma, and this diagnosis was later confirmed by the pathological examination. Postoperatively, the patient was found to have mild right hemiparesis and multiple deficits of the lower cranial nerves (10th through 12th cranial nerves). He required percutaneous gastrostomy and tracheostomy. He also had paralysis of one vocal cord and gait disturbances that gradually improved. Postoperatively hydrocephalus developed, and was treated by inserting a programmable ventriculoperitoneal shunt. Using a conformal four-field technique, a total radiation dose of $5040 \mathrm{cGY}$ was applied to the tumor site in 28 fractions, allowing a $3-\mathrm{cm}$ margin. At follow up 4 years after surgery, the patient had no evidence of tumor recurrence. 
A 36-year-old man, the son of the patient previously described, presented with a 1-year history of recurring headaches and a 2-week history of vomiting. He denied any seizures, gait difficulty, weakness, or numbness. The patient's past medical history was unremarkable.

His neurological examination revealed no focal deficits. The rest of his physical examination was unremarkable, and no clinical signs of neurofibromatosis were present.

An MR image of the brain revealed a $2.5 \times 3-\mathrm{cm}$ enhancing mass arising from the inferior aspect of the fourth ventricle and extending caudally through the foramen magnum for approximately $1 \mathrm{~cm}$. There was also anterior displacement of the medulla, which was abutting the clivus (Fig. 1). Minimal prominence of the fourth ventricle was also noted. An MR image of the spinal axis revealed no drop metastases; CT scans of the chest, abdomen, and pelvis revealed no abnormalities.

He underwent a midline suboccipital craniotomy with cranial nerve electrophysiological monitoring for tumor extirpation. Microscopic and immunohistochemical examinations revealed a tanycytic, well-differentiated ependymoma (World Health Organization Grade II tumor). The resected specimen demonstrated elongated cells with a vaguely fascicular architecture and rare to obscure rosettes. A postoperative MR image confirmed gross total resection of the tumor (Fig. 2). The patient had an uneventful postoperative course and was neurologically intact when he was discharged home. A total 5040-cGy dose in 28 fractions was delivered to the tumor, maintaining a $2.5-\mathrm{cm}$ margin. A

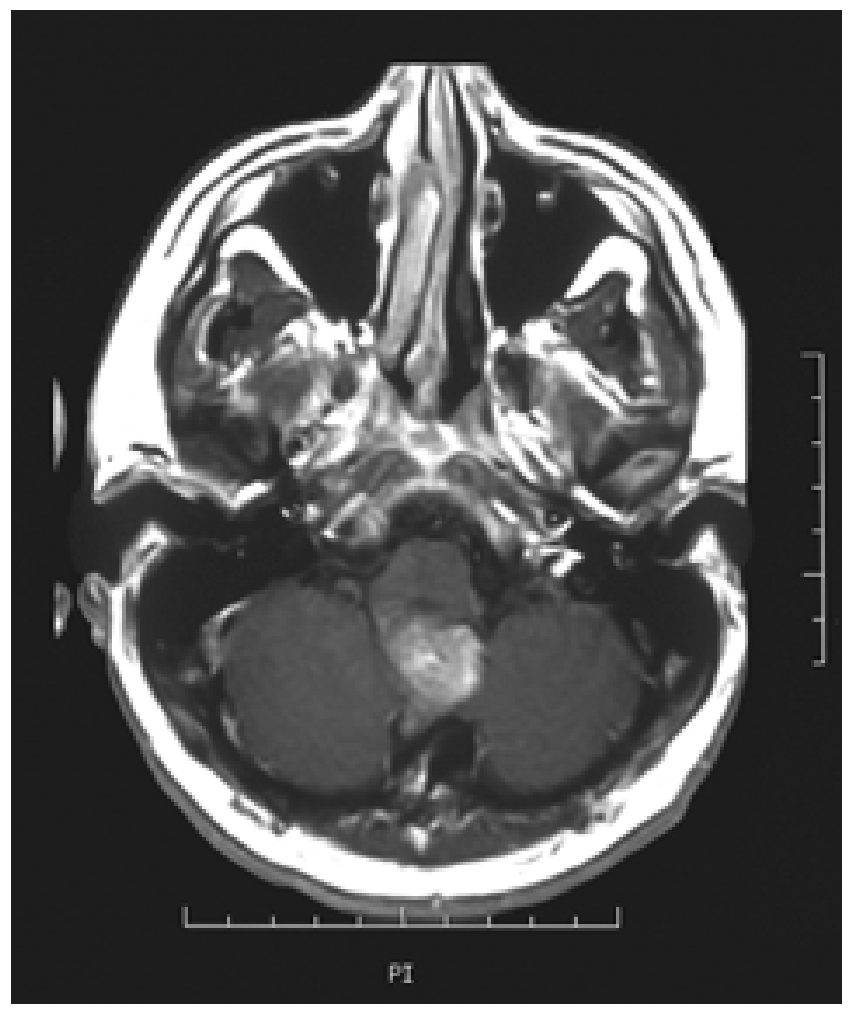

Fig. 1. Preoperative contrast-enhanced $\mathrm{T}_{1}$-weighted MR image obtained revealing a $2.5 \times 3-\mathrm{cm}$ enhancing mass arising from the inferior aspect of the fourth ventricle and extending caudally. Anterior displacement of the medulla, which is abutting the clivus, is also depicted.

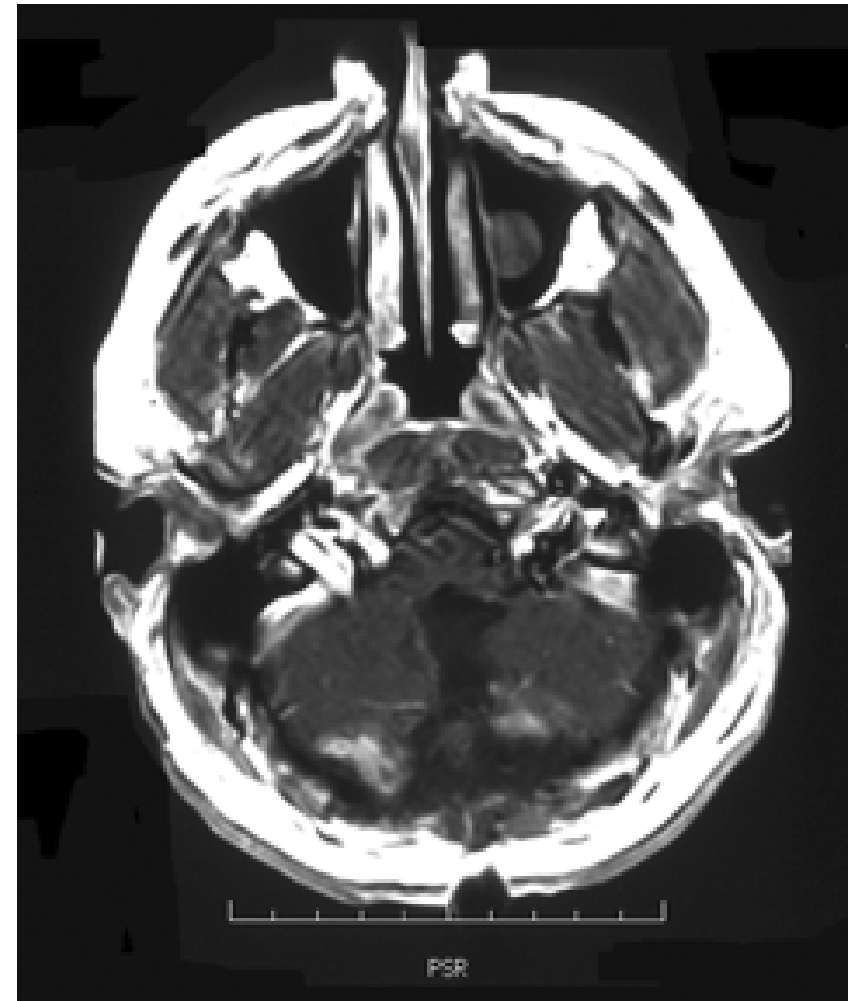

Fig. 2. Postoperative contrast-enhanced $\mathrm{T}_{1}$-weighted MR image (obtained within the first 24 hours after surgery) demonstrating postoperative changes, with cerebrospinal fluid collection at the tumor bed and no evidence of residual tumor.

conformal five-field technique with a 6-MV photon beam and custom blocking was used. The patient has remained asymptomatic and tumor free for 1.5 years.

\section{DISCUSSION}

The existence of familial CNS tumors was first described in the literature in $1896 .{ }^{2}$ Several cases of familial CNS tumors have been described since then. . $^{3,5,8,11,13,17,20,27,29,30}$ Isamat, et al., ${ }^{13}$ have discussed the genetic implications of familial brain tumors and have described six families with a total of 12 members with intracranial tumors: 10 astrocytomas of different grades of malignancy, one glioma, and one ependymoblastoma. In five of the six families, tumors occurred in either siblings or children of the patients. The authors also noted some consistency in the histological and biological characteristics of the tumors observed in a given family, as well as some consistency in the ages at onset of symptoms. It is interesting to note that nine of these patients with familial tumors had type A blood. Acqui, et al., ${ }^{1}$ used the term "occasionally occurring familial brain tumors" to designate cases in which more than one family member harbors a brain tumor that is outside the range of the clinical syndromes in which CNS cancer heredity is well established. In their series, they described three cases of ependymomas, which represented only $2 \%$ (3/169) of the reported cases of occasionally occurring familial brain tumors.

The association of ependymomas with other CNS tumors has been reported by Hemminki, et al., ${ }^{11}$ who have analyzed 
2,060 cases of childhood brain tumors. They have reported that parental colon cancer was associated with CNS ependymoma in offspring (standardized incidence ratio of 3.70). Furthermore, parental CNS tumors were associated with offspring CNS ependymomas (standardized incidence ratio of 2.11). In their study, two patients with ependymomas had mothers with a diagnosis of endometrial cancer (standardized incidence ratio of 2.17). In the cases we presented here, however, there was no family history of colon or other type of cancer.

Furthermore, the literature includes several descriptions of families with more than one member with CNS tumors, at least one of which was an ependymoma in the absence of neurofibromatosis (a condition that predisposes the patient to the development of ependymomas ${ }^{33}$ ) or other hereditary CNS tumor syndromes (Table 1). We reviewed nine previously published studies of families in which ependymomas were diagnosed in at least one family member. $3,5,7,12,20,23,25,27,29$ Including our cases, a total of 29 patients harboring CNS tumors were found. In 19 of these patients (five females and 14 males), ependymomas or subependymomas were diagnosed histologically. The age at presentation ranged between 3 months and 57 years (mean $28.83 \pm 4.34$ ). In regard to the anatomical location of these 19 tumors, 13 $(68.4 \%)$ were infratentorial, two $(10.5 \%)$ were supratentorial, and four $(21.1 \%)$ were spinal. The reported patients were siblings in all but two families in which the patients were fathers and sons and one family in which the patients were mother and son.
More specifically, Sieb, et al., ${ }^{27}$ have described a family with five members harboring CNS tumors and have suggested an autosomal dominant inheritance pattern with relatively high penetrance. In four of these patients, meningioma had been diagnosed, and spinal ependymoma had been diagnosed in one patient. The histological characteristics of the CNS tumors in this family were indistinguishable from the histological features typically seen in sporadic meningiomas or ependymomas. Sato, et al., ${ }^{25}$ have reported the cases of a 3-month-old female with congenital anaplastic ependymoma of the fourth ventricle and her sister, who died when she was 29 days old from a congenital medulloepitheliomatous tumor of the fourth ventricle. The reported ependymoma was characterized by predominantly undifferentiated neuroepithelial cells associated with numerous mitoses, and partially of cells demonstrating differentiation into ependymal cells and astrocytes. Similarly, Ryken, et al., ${ }^{23}$ have reported the occurrence of fourth ventricular subependymoma in a father and a son, suggesting the possibility of direct inheritance. Likewise, Clarenbach, et al., ${ }^{7}$ have described a simultaneous clinical manifestation of subependymomas of the fourth ventricle in monozygotic male twins.

Bromowicz, et al., ${ }^{5}$ have described a family in which spinal ependymoma was diagnosed in the mother and her son underwent resection of a vermian astrocytoma. Bhatt, et al., ${ }^{3}$ have reported the cases of two brothers in whom intracranial neoplasms were diagnosed simultaneously. Parietal oligodendroglioma was diagnosed in the younger, and a left ventricular ependymoma was diagnosed in the older. How-

TABLE 1

Literature review of 27 cases of familial TS*

\begin{tabular}{|c|c|c|c|c|c|}
\hline Authors \& Year & Case No. & Relationship & Age & Location of Lesion & Diagnosis \\
\hline \multirow[t]{2}{*}{ Bromowicz, et al., 1971} & 1 & mother & $30 \mathrm{yrs}$ & thoracic spine & ependymoma \\
\hline & 2 & son & 8 yrs & vermis & astrocytoma \\
\hline \multirow[t]{2}{*}{ Clarenbach, et al., 1979} & 1 & monozygotic twin $\dagger$ & 22 yrs & 4 th ventricle & subependymoma \\
\hline & 2 & monozygotic twin $\dagger$ & 22 yrs & 4 th ventricle & subependymoma \\
\hline \multirow[t]{2}{*}{ Sato, et al., 1984} & 1 & sister & 3 mos & 4 th ventricle & ependymoma \\
\hline & 2 & sister & 29 days & 4th ventricle & medulloepitheliomatous tumor \\
\hline \multirow[t]{5}{*}{ Honan, et al., 1987} & 1 & brother & 13 yrs & pontine tumor & no histological study \\
\hline & 2 & brother & $27 \mathrm{yrs}$ & posterior fossa & subependymoma \\
\hline & 3 & sister & 49 yrs & medulla oblongata & subependymoma \\
\hline & 4 & sister & $57 \mathrm{yrs}$ & posterior fossa & ependymoma \\
\hline & 5 & brother & 54 yrs & posterior fossa & subependymoma \\
\hline \multirow[t]{5}{*}{ Sieb, et al., 1992} & 1 & sister & 30 yrs & lt parietotemporal & meningotheliomatous meningioma \\
\hline & 2 & sister & $17 \mathrm{yrs}$ & cauda equina & meningioma \\
\hline & 3 & sister & $11 \mathrm{yrs}$ & T10-L3 & ependymoma \\
\hline & 4 & son of Case 1 & $15 \mathrm{yrs}$ & lt sphenoid, ON & meningiomas \\
\hline & 5 & daughter of Case 2 & $25 \mathrm{yrs}$ & L-4 & meningotheliomatous meningioma \\
\hline \multirow[t]{4}{*}{ Nijsen, et al., 1994} & 1 & brother & 5 yrs & 4 th ventricle & anaplastic ependymoma \\
\hline & 2 & brother & $6 \mathrm{mos}$ & 4th ventricle & no histological study \\
\hline & 1 & brother & $21 \mathrm{mos}$ & supratentorial intraventricular & anaplastic ependymoma \\
\hline & 2 & brother & $8 \mathrm{mos}$ & posterior fossa & anaplastic ependymoma \\
\hline \multirow[t]{2}{*}{ Ryken, et al., 1994} & 1 & father & $47 \mathrm{yrs}$ & 4th ventricle & subependymoma \\
\hline & 2 & son of Case 1 & $22 \mathrm{yrs}$ & 4 th ventricle & subependymoma \\
\hline \multirow[t]{2}{*}{ Bhatt, et al., 1999} & 1 & brother & $25 \mathrm{yrs}$ & rt parietal & oligodendroglioma \\
\hline & 2 & brother & 32 yrs & lt lat ventricle & ependymoma \\
\hline \multirow[t]{3}{*}{ Yokota, et al., 2003} & 1 & brother & 33 yrs & intramedullary, cervical SC & anaplastic ependymoma \\
\hline & 2 & brother & 44 yrs & intramedullary, thoracic SC & anaplastic ependymoma \\
\hline & 3 & sister & $45 \mathrm{yrs}$ & paravertebral, lower cervical SC & schwannoma \\
\hline \multirow[t]{2}{*}{ Dimopoulos, et al., 2005} & 1 & father & 54 yrs & 4 th ventricle & ependymoma \\
\hline & 2 & son of Case 1 & 36 yrs & 4th ventricle & tanycytic ependymoma \\
\hline
\end{tabular}

$* \mathrm{ON}=$ olfactory nerve; $\mathrm{SC}=$ spinal cord

$\dagger$ The patient was male. 
ever, the fact that the tumors were diagnosed simultaneously suggests the influence of an environmental factor such as an infection. McNally, et al. ${ }^{18}$ have suggested an environmental factor in their epidemiological study, in which they identified space-time clustering and seasonal variation in the cases of ependymoma they examined.

Honan, et al., ${ }^{12}$ have described a family of 11 siblings: three had subependymomas, one an ependymoma, and one a histologically unverified intracranial tumor. Nijssen, et al. ${ }^{20}$ have reported cases of ependymomas in a family in which two healthy brothers each had two affected sons. Three of the cousins had histologically verified anaplastic ependymomas, and the fourth had a neuroradiologically suggested ependymoma. Genotype analysis in one of these tumors showed a subpopulation of tumor cells with monosomy of chromosome 22, supporting the role of a tumor suppressor gene on chromosome 22 in the pathogenesis of familial ependymal tumors. Similarly, Yokota, et al..$^{33}$ have described a four-member Japanese family in which two members had cervical and thoracic spinal cord ependymomas and another had a cervical nerve root schwannoma. Molecular genetic analysis of the spinal anaplastic ependymomas supported the existence of a tumor suppressor gene on chromosome 22 that appears to be involved in the pathogenesis of familial ependymal tumors.

Further cytogenetic studies have shown that loss of chromosome 22 may be the most common genetic abnormality in ependymomas. ${ }^{10,21,24}$ Approximately $30 \%$ of ependymomas demonstrate monosomy of chromosome $22 .{ }^{33}$ Kraus, et al., ${ }^{16}$ who analyzed 53 cases of sporadic ependymal tumors (18 in children and 35 in adults), have found a high frequency of allelic loss on chromosome arm 22q. They have concluded that this region may harbor putative tumor suppressor gene or genes that are involved in the evolution and/or progression of human ependymal tumors. However, the cause or initiating event leading to molecular changes in chromosome 22 is not yet clear. McNally, et al., ${ }^{18}$ have studied the geographical distribution of CNS tumors in children age 0-14 years and have concluded that ependymomas may be associated with a highly mobile transient etiological agent, such as an infection, that occurs in miniepidemics. This conclusion was derived from the observation of space-time clustering and seasonal variation in cases of ependymomas and astrocytomas. We believe that the study of monozygotic twins could help clarify the potential role of environmental factors in the pathogenesis of familial ependymomas.

Several other chromosomal regions, such as 17p13.1, 10q25-q26, and regions of chromosomes 9 and 13, have also been implicated in the pathogenesis of ependymomas. ${ }^{14,33}$ Von Haken, et al. ${ }^{31}$ have studied a series of 16 intracranial and two spinal sporadic pediatric ependymomas and have suggested that the loss of chromosome arm 17p DNA sequences is common in sporadic pediatric ependymomas and that, in contrast to ependymomas in adults, deletion of chromosome arm 22q sequences is rare.

\section{CONCLUSIONS}

Our presented cases of intracranial, infratentorial familial ependymomas, together with the similar cases reported in the literature, further support the role of cytogenetics in the pathogenesis of these rare tumors. Although the exact incidence of familial ependymomas is unknown, the treating physician should be aware of this entity and pay particular attention to the family history of patients presenting with clinicoradiographic signs suggestive of ependymomas, to detect cases of these tumors in the patient's family. Further cytogenetic studies of familial ependymomas might reveal important information regarding the pathophysiological characteristics of these tumors and lead to better patient care.

\section{References}

1. Acqui M, Ferrante L, Vagnozzi R, et al: Occasionally-occurring familial brain tumors (OFBT). Reports of cases and review of the literature. J Neurosurg Sci 33:263-269, 1989

2. Besold G: Uber zwei Falle von Gehirntumor (Haemangiosarkom oder sogenanntes Periepitheliom in der Gegend des dritten Ventrikels) bei zwei Geschwistern. Dtsch Z Nervenheilkd 8: 49-74, 1896

3. Bhatt AR, Mohanty S, Sharma V, et al: Familial gliomas: a case report. Neurol India 47:136-138, 1999

4. Bijlsma EK, Voesten AM, Bijleveld EH, et al: Molecular analysis of genetic changes in ependymomas. Genes Chromosomes Cancer 13:272-277, 1995

5. Bromowicz J, Araszkiewicz H, Kinderman B: [Familial occurrence of neoplasms of the central nervous system.] Neurol Neurochir Pol 5: 721-725, 1971 (Polish)

6. Burger PC, Scheithauer BW: Tumors of the central nervous system, in Atlas of Tumor Pathology. Washington DC: Armed Forces Institute of Pathology, 1994, pp 317-320

7. Clarenbach P, Kleihues P, Metzel E, et al: Simultaneous clinical manifestation of subependymoma of the fourth ventricle in identical twins. Case report. J Neurosurg 50:655-659, 1979

8. de Tribolet N, Deruaz JP, Zander E: Familial gliomas. Neurochirurgia (Stuttg) 22:225-228, 1979

9. Dohrmann GJ, Farwell JR, Flannery JT: Ependymomas and ependymoblastomas in children. J Neurosurg 45:273-283, 1976

10. Griffin CA, Long PP, Carson BS, et al: Chromosome abnormalities in low-grade central nervous system tumors. Cancer Genet Cytogenet 60:67-73, 1992

11. Hemminki K, Li X, Vaittinen P, et al: Cancers in the first-degree relatives of children with brain tumors. Br J Cancer 83: 407-411, 2000

12. Honan WP, Anderson M, Carey MP, et al: Familial subependymomas. Br J Neurosurg 1:317-321, 1987

13. Isamat F, Miranda AM, Bartumeus F, et al: Genetic implications of familial brain tumors. J Neurosurg 41:573-575, 1974

14. Kim BS, Roonprapunt C, LaMarca V, et al: The current management of intracranial ependymomas in children. Ann Neurosurg 2:1-10, 2002

15. Kramer DL, Parmiter AH, Rorke LB, et al: Molecular cytogenetic studies of pediatric ependymomas. J Neurooncol 37: 25-33, 1998

16. Kraus JA, de Millas W, Sorensen N, et al: Indications for a tumor suppressor gene at 22q11 involved in the pathogenesis of ependymal tumors and distinct from hSNF5/INI1. Acta Neuropathol (Berl) 102:69-74, 2001

17. Leblanc R, Lozano A, Robitaille Y: Familial mixed oligodendrocytic-astrocytic gliomas. Neurosurgery 18:480-482, 1986

18. McNally RJ, Alston RD, Eden TO, et al: Further clues concerning the aetiology of childhood central nervous system tumors. Eur J Cancer 40:2766-2772, 2004

19. Neumann E, Kalousek, DK, Norman MG, et al: Cytogenetic analysis of 109 pediatric central nervous system tumors. Cancer Genet Cytogenet 71:40-49, 1993

20. Nijssen PC, Deprez RH, Tijssen CC, et al: Familial anaplastic ependymoma: evidence of loss of chromosome 22 in tumor cells. J Neurol Neurosurg Psychiatry 57:1245-1248, 1994 


\section{Familial intracranial ependymomas}

21. Ransom DT, Ritland SR, Kimmel DW, et al: Cytogenetic and loss of heterozygosity studies in ependymomas, pilocytic astrocytomas and oligodendrogliomas. Genes Chromosomes Cancer 5:348-356, 1992

22. Russell DS, Rubinstein LJ: Pathology of Tumors of the Nervous System, ed 4. Baltimore: Williams and Wilkins, 1977, pp 203-226

23. Ryken TC, Robinson RA, VanGilder JC: Familial occurrence of subependymoma. Report of two cases. J Neurosurg 80: 1108-1111, 1994

24. Sainati L, Montaldi A, Putti MG, et al: Cytogenetic t(11;17) (q13;q21) in a pediatric ependymoma. Is 11q13 a recurring breakpoint in ependymomas? Cancer Genet Cytogenet 59: 213-216, 1992

25. Sato T, Shimoda A, Takahashi T, et al: Congenital anaplastic ependymoma: a case report of familial glioma. Childs Brain 11:342-348, 1984

26. Sawyer JR, Sammartino G, Husain M, et al: Chromosome aberrations in four ependymomas. Cancer Genet Cytogenet 74: 132-138, 1994

27. Sieb JP, Pulst SM, Buch A: Familial CNS tumors. J Neurol 239:343-344, 1992

28. Svien HJ, Mabon RF, Kernohan JW, et al: Ependymoma of the brain: pathologic aspects. Neurology 3:1-15, 1953
29. Turowski K: [Familial gliomas.] Neurol Neurochir Pol 12: 85-87, 1978 (Polish)

30. Uzal D, Ozyar E, Tukul A, et al: Familial glioma in two siblings. Radiat Med 14:43-47, 1996

31. von Haken MS, White EC, Daneshvar-Shyesther L, et al: Molecular genetic analysis of chromosome arm $17 \mathrm{p}$ and chromosome arm 22q DNA sequences in sporadic pediatric ependymomas. Genes Chromosomes Cancer 17:37-44, 1996

32. Wernicke C, Thiel G, Lozanova T, et al: Involvement of chromosome 22 in ependymomas. Cancer Genet Cytogenet 79: 173-176, 1995

33. Yokota T, Tachizawa T, Fukino K, et al: A family with spinal anaplastic ependymoma: evidence of loss of chromosome $22 \mathrm{q}$ in tumor. J Hum Genet 48:598-602, 2003

Manuscript received November 15, 2005.

Accepted in final form December 21, 2005.

Address reprint requests to: Kostas N. Fountas, M.D, Ph.D, 840 Pine Street, Suite 880, Macon, Georgia 31201. email: knfountasmd @ excite.com. 